\title{
Perancangan Infografis Interaktif 2d Sebagai Media Informasi Krs Online Bagi Mahasiswa Baru Perguruan Tinggi Asia Malang
}

\author{
Tengky Triono Bagus M 1 ${ }^{1}$, Brenda Dessiyani Ismanto ${ }^{2}$ \\ 1,2 Teknik Informatika, STMIK ASIA Malang \\ 1'mesinkaraoke@yahoo.com, ${ }^{2} 13211135 @$ stmikasia.ac.id
}

\begin{abstract}
ABSTRAK
Pada awal tahun 2016 Perguruan Tinggi Asia memutuskan menggunakan sistem baru dalam proses penyusunan KRS yaitu kartu rencana studi online. Penggunaan system KRS online memiliki sedikit kendala karena sistem yang baru ini kurang sosialisasi penggunaannya sehingga masih banyak para mahasiswa yang belum mengerti dengan alur pengisian KRS online tersebut. Karena kendala dalam alur pengisian KRS Online maka dipilihlah media media infografis interaktif untuk memberikan pemahaman dan sosialisasi tentang KRS Online kepada para mahasiswa khususnya mahasiswa baru yang baru menjalani masa kuliah maka diperlukan sebuah media sebagai media informasi.

Media infografis interaktif dibuat dengan penggabungan gambar, teks, video, audio dan animasi 2 dimensi. Didalam media ini terdapat 3 menu yaitu menu about berisi tentang rangkuman singkat isi dari aplikasi dan asia secara singkat, alur KRS berisi proses alur pengisian KRS Online, dan profil author berisi tentang data diri pembuat media ini. Pada media ini juga terdapat tombol exit, tombol maximaze, tombol gambar didalam alur KRS menuju halaman keterangan alur KRS dan tombol next back. Warna yang digunakan dalam media ini yaitu biru, jingga dan hitam putih disuguhkan lebih muda. Sedangkan teks yang dipakai adalah font Arial, Arial Black, Arial Rounded MT Bold, dan Arial Narrow.

Melalui media infografis interaktif ini para mahasiswa khususnya para mahasiswa baru yang baru menjalani masa kuliah yang tidak mengerti dan bingung dapat memahami bagaimana alur pengisian KRS online yang masih baru dijalankan oleh Asia Malang. Berdasarkan hasil kuesioner pengujian media infografis interaktif terhadap 60 orang, maka dapat disimpulkan dengan adanya media infografis interaktif $32 \%$ mahasiswa sangat mengerti tentang alur pengisian krs online. 68\% responden setuju dan cocok penggunaan media ini sebagai media informasi alur proses pengisian krs online.
\end{abstract}

Kata Kunci: KRS Online, Media Infografis Interaktif, Media Informasi, Infografis, Interaktif.

\begin{abstract}
In early 2016 Asia University decided to use a new system in the process of drafting the KRS namely an online study plan card. The use of Online KRS system has few constraints because the new system is less socialization of its use so there are still many students who have not understood with the flow of filling Online KRS. Due to obstacles in the flow of filling Online KRS then selected an interactive infographic media to provide understanding and socialization of Online KRS to the students, especially new students who are just undergoing college.

Interactive infographic media is created by combining images, text, video, audio and 2-dimensional animation. In this media there are 3 menus: the menu about contains a brief summary of the application contents and a glance of Asia, KRS flow contains the process of filling Online KRS, and author's profile contains about the data of this media maker. In this media there are also exit button, maximaze button, picture button in KRS path to KRS flow description page and next back button. The colors used in this medium are blue, orange, black and white served younger. While the text used is Arial font, Arial Black, Arial Rounded MT Bold, and Arial Narrow.

Through this interactive infographic media, the students especially the new students who just undergo a period of unfamiliar and confused college can understand how the flow of filling Online KRS is still being run by Asia Malang. Based on the result of questionnaire of interactive infographic media testing on 60 people, it can be concluded with the interactive infographic media $32 \%$ of
\end{abstract}


students were very understanding about the flow of filling Online KRS. 68\% of respondents agreed and suitable use of this media as a medium of information flow process filling Online KRS.

Keywords: Online KRS, Interactive Infographic Media, Information Media, Infographic, Interactive.

\section{PENDAHULUAN}

Informasi sangat penting dalam kehidupan manusia karena informasi dapat menambah pengetahuan dan mengetahui hal-hal apa saja yang baru di lingkungan pada saat ini. Dengan berkomunikasi manusia diharapkan dapat mengetahui dan memahami semua informasi yang diperlukan. Namun tidak semua orang dapat memahami dan mengerti informasi terbaru yang ada disekitar dengan baik sehingga diperlukan sebuah media informasi.

Perguruan Tinggi Asia Malang merupakan salah satu perguruan tinggi swasta di Malang. Asia merupakan salah satu perguruan tinggi berbasis komputer di Kota Malang. Dari mulai awal berdiri sampai sekitar akhir tahun 2015, Perguruan Tinggi Asia dalam proses penyusunan kartu rencana studi masih menggunakan metode manual bisa disebut dengan KRS offline. Penggunaan KRS offline memiliki beberapa masalah dalam pelaksanaannya misalnya para mahasiswa harus datang ke kampus untuk melakukan pengisisan jadwal kuliah. Selain itu proses pengisiannya pun harus bergantian dengan banyaknya mahasiswa yang tidak sesuai dengan jumlah media komputer yang ada di laboraturium. Menilai dari kurang berhasilnya sistem KRS offline, akhirnya sekitar awal tahun 2016

Perguruan Tinggi Asia memutuskan menggunakan sistem baru dalam proses penyusunan KRS yaitu kartu rencana studi online. Penggunaan sistem KRS online pun masih ada sedikit masalah karena sistem yang baru ini kurang sosialisasi penggunaannya sehingga masih banyak para mahasiswa yang belum mengerti dengan alur pengisian KRS online tersebut. Karena kurangnya sosialisasi itulah maka dipilihlah media yang tepat untuk penyampaian informasi yang efektif.

Kartu Rencana Studi Online adalah program terbaru dari perguruan tinggi ASIA Malang yang berhubungan dengan proses penjadwalan mata kuliah. Pada dasarnya KRS Online merupakan sistem informasi berbasis web yang bermanfaat untuk membantu dalam proses penyusunan KRS yang nantinya akan digunakan oleh Mahasiswa. Mahasiswa hanya perlu memilih mata kuliah yang ditampilkan atau ditawarkan pada sistem ini dimana mata kuliah yang ditawarkan atau ditampilkan sudah disetujui oleh kepala jurusan dan akademik. Untuk memberikan pemahaman tentang KRS Online kepada mahasiswa perguruan tinggi ASIA Malang khususnya mahasiswa baru yang baru menjalani masa kuliah maka diperlukan sebuah media edukasi sebagai media informasi adalah media infografis interaktif.

Diharapkan dengan menggunakan infografis interaktif dapat menjawab pertanyaan latar belakang di atas. Infografis interaktif adalah jenis infografis yang paling kompleks jika dibandingkan dengan infografis statis dan infografis animasi. Pada infografis ini, target yang menjadi sasaran penyajian informasi bisa melakukan interaksi terhadap infografis yang disajikan. Untuk mewujudkan infografis interaktif yang baik, dibutuhkan kerjasama dengan developer atau programmer supaya animasi maupun pemrograman interaksi bisa dijalankan dengan lancar. (Lankow, 2014) 
Dengan adanya masalah tersebut, maka dibuatlah sebuah media infografis interaktif. Pemilihan infografis berbasis interaktif disebabkan karena infografis interaktif dapat dijalankan diperangkat komputer dan berbasis informasi dengan berisi tampilan yang cukup menarik, sederhana, dan memilik penjelasan dalam bentuk animasi setiap informasi, serta pengguna dapat berinteraksi dengan informasi yang ditampilkan melalui user interface yang telah didesain. Dengan media infografis interaktif pengguna dapat dengan mudah menggunakan sesuai keinginan mengeksplorasi informasi yang ingin didapatkan.

\section{PEMBAHASAN}

Dari identifikasi data pada bagian sebelumnya diperoleh kesimpulan bahwa:

1. Media ini digunakan untuk memberi informasi kepada para mahasiswa khususnya mahasiswa baru yang berusia kisaran 17-22 tahun agar mengetahui tentang alur proses pengisian Kartu Rencana Studi Online yang ada didalam media infografis interaktif ini.

2. Penggunanya adalah mahasiswa Perguruan Tinggi ASIA terutama para mahasiswa baru.

3. Aplikasi ini diharapkan menjadi media bantu informasi KRS online yang merupakan program baru dari ASIA Malang

4. Di dalam aplikasi tersebut berisi tentang alur proses pengisian Kartu Rencana Studi Online.

Dari analisa data yang didapat maka, dapat diambil solusi sebagai berikut:

1. Media akan digunakan oleh mahasiswa usia 17-22 tahun jadi, desain harus minimalis dan menarik untuk para mahasiswa namun harus elegan dan agar lebih terlihat modern maka digunakan design gambar 2D pada desain tampilan antarmukanya.

2. Media ini digunakan sebagai media informasi jadi, harus dapat menyampaikkan informasi yang akan disampaikan dengan tepat kepada para mahasiswa.

3. Aplikasi ini haruslah bersifat infografis interaktif bagi pengguna, agar informasi dapat tersampaikan kepada pengguna dengan baik. Maka pada media ini akan disertakan kontak yang diharapkan para pengguna dapat bertanya tentang hal yang berkaitan dengan informasi KRS online yang belum dimengerti.

Solusi yang didapat maka direalisasikan ke dalam konsep bentuk digram alur apilkasi. Berikut adalah diagram alur dari aplikasi ini.

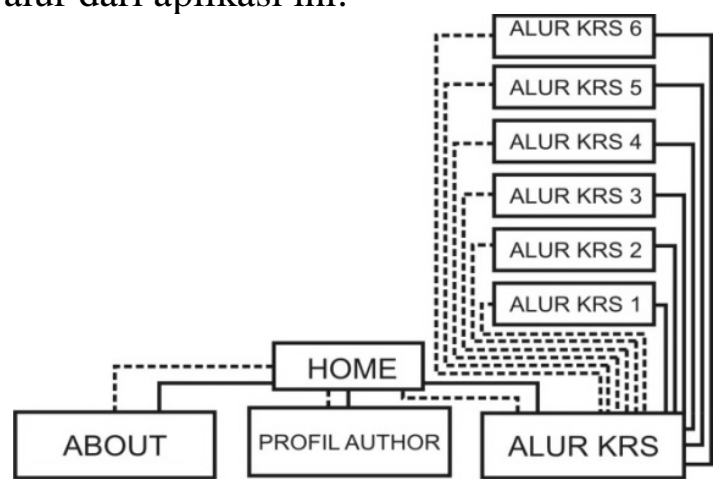

Gambar 1. Diagram Alur Aplikasi

Adapun diagram alur aplikasi seperti terdapat pada gambar 3.1. Pada tampilan menu utama akan disuguhkan 5 tombol : 3 tombol menu utama terdiri dari: tombol alur KRS, tombol profil author, dan tombol about. Kemudian 2 tombol pendukung (berada pada menu 
utama) yang terdiri dari: tombol maximaze untuk memperbesar tampilan, menu exit untuk keluar dari aplikasi tersebut. Tombol about, alur KRS, dan profil author akan berada di bawah tengah dengan posisi berurutan ke samping kanan. Tombol alur krs akan menuju menu proses alur KRS yang berisi proses alur pengisian KRS online dengan beberapa tombol utama yang berisikan keterangan dalam bentuk video. Tombol profil author akan menuju ke menu yang berisi profil author. Tombol about akan menuju ke menu yang berisi tentang profil ASIA dan inti isi yang ada dalam aplikasi. Tombol maximaze berada pada bagian pojok kanan atas layar untuk memperbesar tampilan. Pada sebelah kanan tombol maximaze terdapat tombol exit untuk keluar dari aplikasi tersebut. Tombol back dan next akan berada pada halaman keterangan alur KRS berada pada posisi kanan bawah layar yang berfungsi untuk kembali atau lanjut ke menu sebelum atau sesudahnya.

Untuk mempermudah pengguna dalam berinteraksi pada halaman alur KRS yang terdapat pada media infografis interaktif ini, maka diberikan beberapa tombol dalam bentuk karakter berguna membantu dalam menggunakan. Karakter-karakter tersebut nantinya juga akan dilengkapi dengan keterangan singkat jika kursor diarahkan ke karakter tersebut. Kegunaannya agar pengguna dapat memahami apa yang dimaksudkan dengan tombol karakter tersebut. Pada tabel 3.2 akan disebutkan tombol- tombol navigasi tersebut.

Tabel 1. Desain Karakter

\begin{tabular}{|c|l|}
\hline Gambar Karakter & \multicolumn{1}{|c|}{ Deskripsi } \\
\hline Penggunaan gambar yang terdiri \\
dari tiga orang untuk proses mahasiswa \\
datang ke baa kampus asia meminta id \\
dan password simaka. Alasannya karena \\
mahasiswa akan berurusan dengan orang \\
yang berada dibagian akademik untuk \\
meminta id dan password.
\end{tabular}




\begin{tabular}{|l|l|} 
Penggunaan gambar kertas dan kaca \\
pembesar untuk proses mahasiswa diberi \\
kesempatan untuk mengganti mata kuliah \\
yang diajukan, sampai disetujui dosen wali \\
karena kaca pembesar identik dengan \\
meneliti dimaksudkan dosen telah \\
memeriksa pengajuan matakuliah \\
mahasiswa dan diberi kesempatan \\
memperbaiki mata kuliah yang ditolak.
\end{tabular}


Tabel 1. Lanjutan

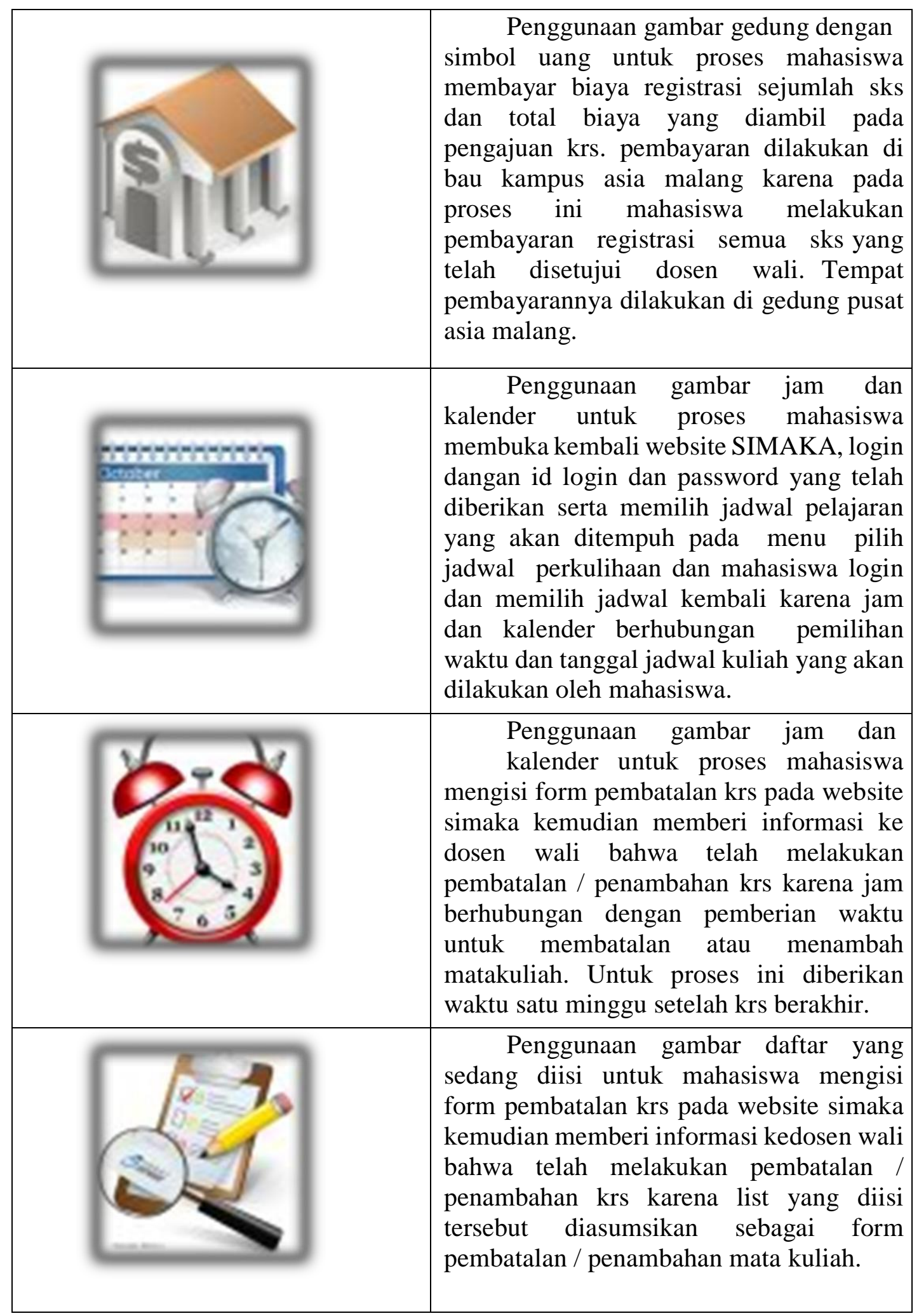


Tabel 1. Lanjutan

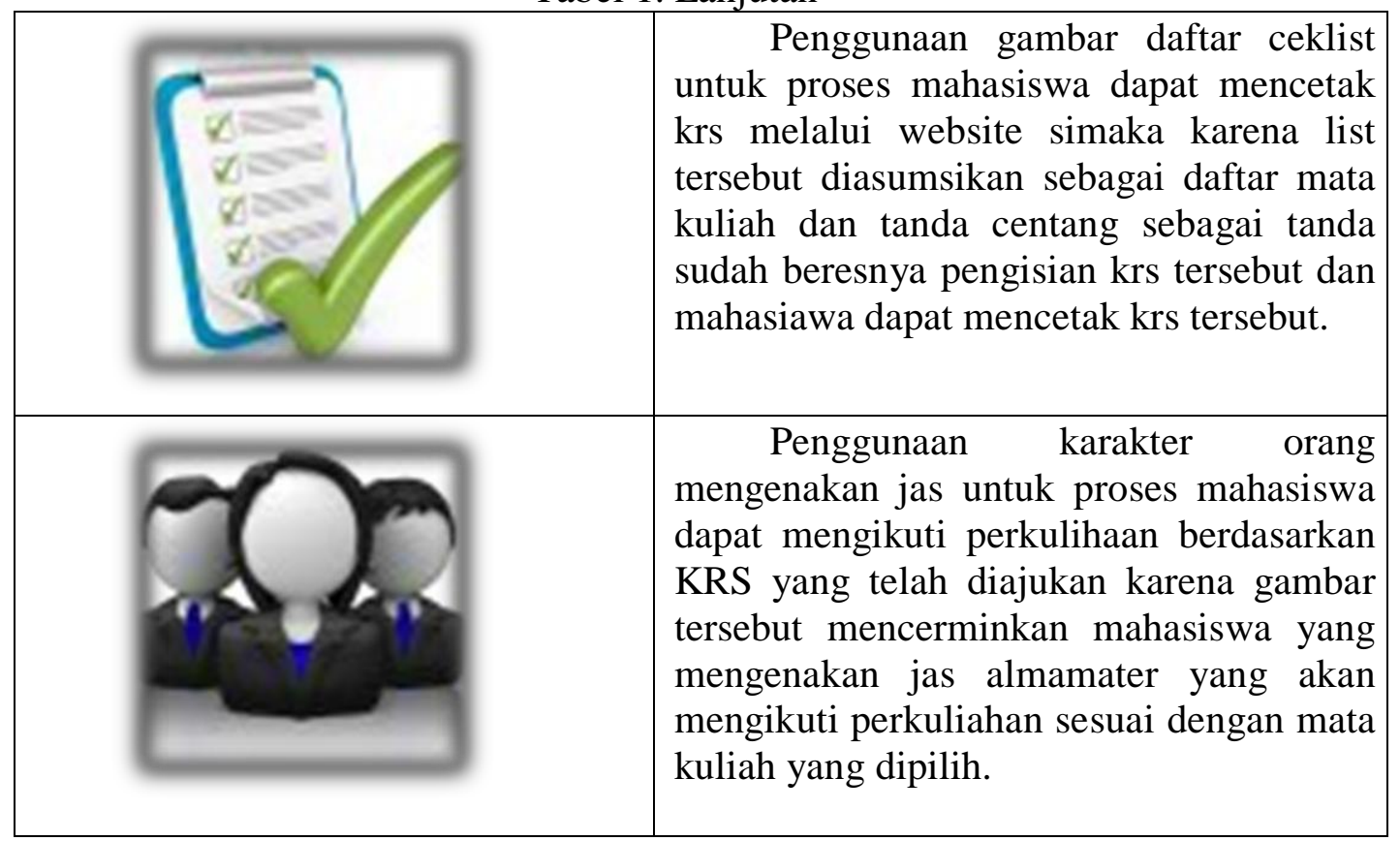

Untuk mempermudah pengguna dalam berinteraksi dengan media infografis interaktif ini, maka diberikan tombol-tombol sebagai pembantu dalam menggunakan aplikasi. Dan tombol-tombol tersebut beberapa nantinya juga akan dilengkapi dengan keterangan singkat atau nama dari tombol tersebut agar pengguna dapat memahami kegunaan dari tombol tersebut. Pada tabel 1 akan disebutkan tombol-tombol navigasi tersebut.

Konsep desain yang dibuat agar nampak edukatif bagi pengguna aplikasi ini, perlu memahami beberapa konsep dasar dalam mengolah perancangan sebuah aplikasi yang infografis dan interaktif. Konsep perancangan aplikasi ini adalah minimalis atau sederhana agar menonjolkan informasi yang ingin disampaikan kepada para mahasiswa ASIA Malang khususnya mahasiswa baru, sehingga pengguna dapat terfokus kepada informasi alur pengisisan KRS bukannya ke desain pelengkap pada aplikasi nantinya. Pada bagian ini akan dijelaskan tentang konsep desain / perancangan media infografis interaktif, tampilan layout merupakan rancangan awal dari ide yang pertama dan direalisasikan dari diagram alur kemudian dibangun dan memberikan gambaran dari media pembelajaran yang akan dibuat.

Warna yang akan digunakan dalam aplikasi ini adalah warna jingga biru dan hitam putih. Namun, disuguhkan dalam penggayaan warna yang lebih muda agar sesuai dengan konsep desainnya yaitu flat design. Hal ini dilakukan untuk memberi kesan sederhana namun menarik dari konsep flat design yang digunakan, yang tidak perlu menggunakan terlalu banyak warna. Warna jingga biru dan hitam putih pada aplikasi ini diambil dari warna yang terdapat pada logo perguruan tinggi Asia Malang. Tiga warna tersebut digunakan untuk background dan tombol menu utama yang disuguhkan. Digunakan warna netral (hitam dan putih) sebagai komplementer pada desain tampilan aplikasi ini. Berikut adalah warna yang digunakan untuk tampilan aplikasi.

Jenis huruf yang akan digunakan adalah yang sederhana, sebab tujuan utama adalah menyampaikan materi infografis interaktif. Jadi yang harus dominan adalah informasi. Didalam aplikasi tersebut dipilih font Arial, Arial Black, Arial Rounded MT Bold, dan Arial Narrow. Jenis font tersebut termasuk dalam kategori san serif/tanpa sirip. Alasan pemilihan jenis font tersebut karena bentuk fontnya di sesuaikan dengan aturan font yang 
digunakan di perguruan tinggi Asia Malang tidak hanya itu saja penggunaan font tersebut agar terkesan sederhana, rapih, dan memiliki tingkat keterbacaan yang tinggi di setiap hurufnya

Berikut layout awal perancangan media infografik interaktif :

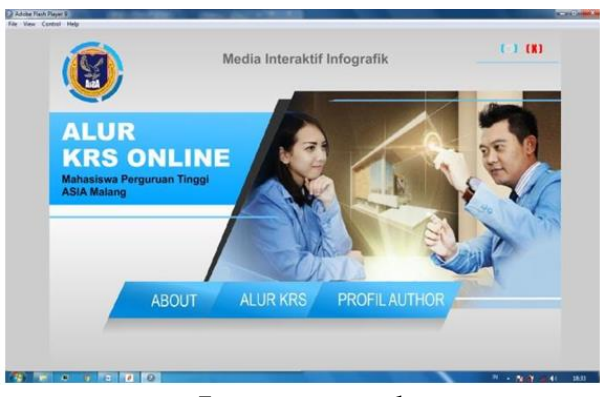

Layout awal

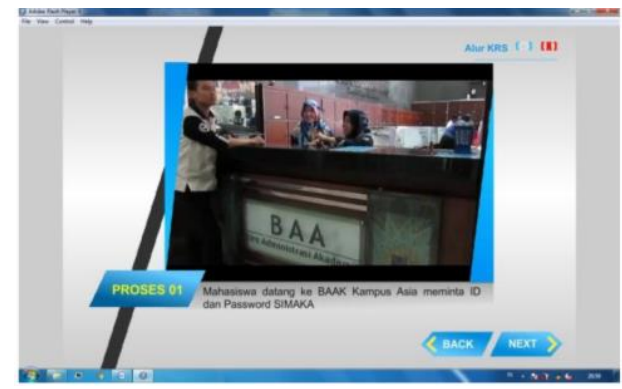

Layout Keterangan Alur KRS Online

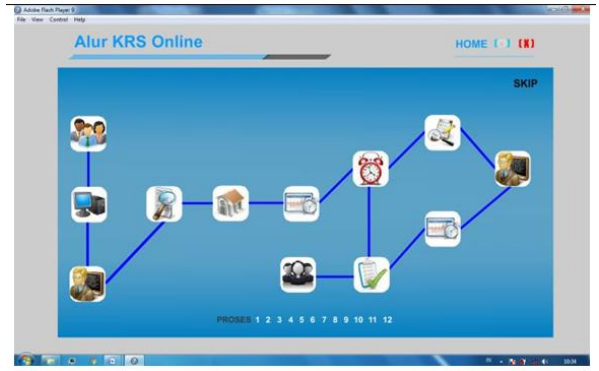

Layout menu Alur KRS Online

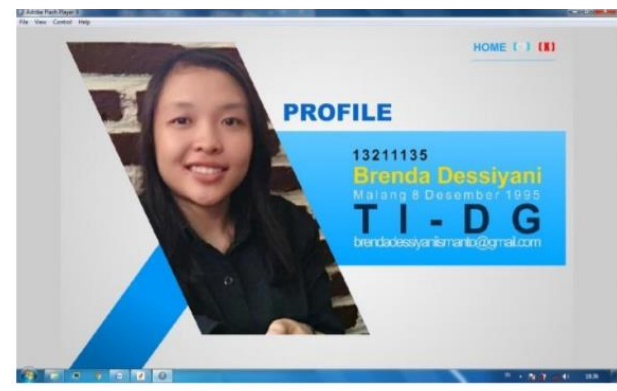

Layout Author

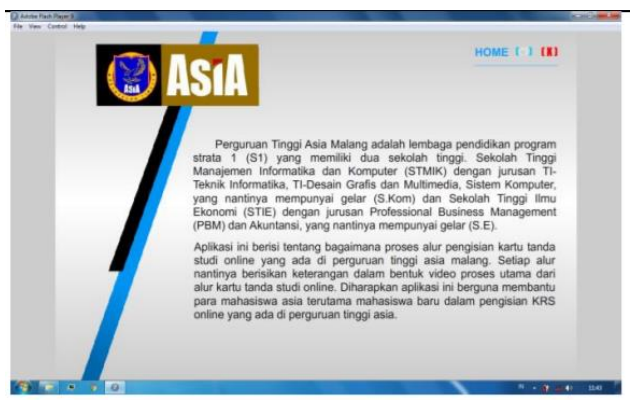

Layout Menu About

Gambar 2. Layout Infografis Interktif KRS Online

\section{KESIMPULAN}

Dari penelitian ini dapat disimpulkan bahwa infografis interaktif 2D sebagai media informasi KRS online bagi mahasiswa baru Asia malang adalah :

Melalui media infografis interaktif ini pengguna dapat mengerti bagaimana alur pengisian KRS online yang masih baru dijalankan oleh Asia Malang. Media infografis interaktif menampilkan informasi melalui teks, video, audio dan gerakan yang terbentuk menjadi tampilan animasi 2 dimensi yang menarik dan mudah digunakan oleh pengguna. Dalam penjelasan alur pengisian KRS online menggunakan video, audio dan teks pada media infografis interaktif ini sehingga dapat memudahkan pengguna yaitu para mahasiswa khususnya mahasiswa baru dapat memahami penjelasan dari alur tersebut. 
Untuk dapat mengetahui sejauh mana manfaat yang didapat oleh audien setelah melihat secara langsung media infografis interaktif ini maka peneliti melaukan uji coba dengan mengajukan sepuluh pernyataan melalui kuesioner, kuisioner dibagi kepada 60 orang yang memiliki berbagai latar belakang berbeda. Setelah melakukan uji coba melalui kuesioner akhirnya didapatkan hasil $66 \%$ para mahasiswa yang kurang mengetahui cara pengisian alur krs online dengan benar. Dengan adanya media infografis interaktif 32\% mahasiswa merasa terbantu sekali untuk mengerti tentang alur pengisian krs online. $62 \%$ Mahasiswa juga menilai tampilan media infografis interaktif sudah menarik untuk dilihat dari sisi desain grafis maupun animasinya. Materi yang disampaikan pun $72 \%$ mahasiswa menilai sudah cukup sesuai dengan materi yang ada. Dalam hal penggunaan media infografis interaktif $15 \%$ responden setuju sekali bahwa media ini sangat mudah digunakan.

Pemilihan media infografis interaktif sebagai media informasi alur krs $68 \%$ responden dinilai cukup setuju dan merasa cocok dengan penggunaan media ini sebagai media informasi alur proses pengisian krs online. Media infografis interaktif ini didistribusikan dalam bentuk softcopy dibagikan ke lab komputer yang ada di Perguruan Tinggi ASIA Malang yang memiliki perangkat komputer yang telah terinstall aplikasi Adobe Flash Player.

\section{DAFTAR PUSTAKA}

Arofat, Saiful. The power Of Corel Draw. Jakarta. Elex Media Komputindo. 2005.

Arsyad, Azhar. Media Pembelajaran. Jakarta. PT Raja Grafindo Persada. 2011.

Darmaprawira, Sulasmi. Warna: Teori dan Kreativitas Penggunaannya ed Kedua. Bandung. Penerbit ITB. 2002.

Degeng, Sudana. Ilmu Pengajaran Taksonomi Variabel. Jakarta. Direktorat Jendral Pendidikan Tinggi. 1989.

Hendratman, Hendi. Tips $n$ Trix Computer Graphics Design. Bandung. Informatika. 2008. Lankow, A Jason. Infographic : Kedasyatan Cara Bercerita Visual. Jakarta.

Gramedia Pustaka Utama. 2014.

Nyoman I Gusti, Ni Nyoman. Desain Komunikasi Visual. Indonesia. ANDI. 2015.

Rustan, Surianto. Huruf, Font, dan Tipografi. Jakarta. Gramedia Pustaka Utama. 2011.

Sanyoto, Sadjiman Ebdi. Nirmana: Elemen-Elemen Seni Rupa Dan Desain. Yogyakarta. Jalasutra. 2010. 